Article

\title{
Known and Emerging Mycotoxins in Small- and Large-Scale Brewed Beer
}

\author{
Terenzio Bertuzzi *, Silvia Rastelli, Annalisa Mulazzi, Gianluca Donadini and Amedeo Pietri
}

Department of Animal Science, Food and Nutrition, Faculty of Agricultural, Food and Environmental Sciences, UCSC, Via Emilia Parmense, 84, 29122 Piacenza, Italy; silvia.rastelli@unicatt.it (S.R.); annalisa.mulazzi@unicatt.it (A.M.); gianluca.donadini@unicatt.it (G.D.); amedeo.pietri@unicatt.it (A.P.)

* Correspondence: terenzio.bertuzzi@unicatt.it; Tel.: +39-0523-599262

Received: 29 May 2018; Accepted: 14 June 2018; Published: 20 June 2018

\begin{abstract}
The occurrence of ochratoxin A (OTA), deoxynivalenol (DON), sterigmatocystin (STC), and citrinin (CIT) was evaluated in samples of small- (SS) and large-scale (LS) brewed beer. The analyses were conducted using HPLC-FLD for OTA, GC-MS for DON, and LC-MS/MS for STC and CIT. During 2017, a total of 83 samples of SS and LS brewed beer (42 and 41, respectively) were sampled; for both types of beer, the most sold beers in Italy were collected. CIT was never detected in any sample, whereas OTA, DON, and STC prevalence was $45.8 \%, 25.3 \%$, and $27.7 \%$, respectively. The mean and maximum values for OTA, DON, and STC were 0.007 and 0.070; 8.6 and $99 ; 0.001$ and $0.018 \mu \mathrm{g} / \mathrm{kg}$, respectively. No significant difference was observed between the SS and LS beers. The results of this survey showed a low contamination; the levels found should not represent a serious risk for consumers' health.
\end{abstract}

Keywords: ochratoxin A; deoxynivalenol; sterigmatocystin; citrinin

\section{Introduction}

Mycotoxins are naturally occurring secondary metabolites of fungi that can be produced on a wide range of agricultural commodities. Cereals used in beer production, particularly barley, wheat, and sometimes maize, can be contaminated with different mycotoxins. Under favourable ecological conditions, cereal contamination can occur both in field and during storage, and also during malting. Previous studies, investigating the fate of naturally occurring or spiked mycotoxins at various stages of the brewing process, have demonstrated that mycotoxins can be transmitted from contaminated grains into beer [1-4]. Considering the most known mycotoxins, numerous surveys have reported the occurrence of ochratoxin A (OTA) and deoxynivalenol (DON) in several beer samples, while zearalenone and aflatoxins were rarely detected. Fumonisins were found only when maize was used in the brewing process. In addition to known mycotoxins, for which maximum levels in food are enforced, also, the so-called, currently unregulated, "emerging mycotoxins", can frequently occur in agricultural products. Among these toxins, EFSA (European Food Safety Authority) requested data on the presence of sterigmatocystin (STC) and citrinin (CIT) in food [5,6]. All these mycotoxins have been associated with human and animal diseases; further, the International Agency for Research on Cancer (IARC) has classified OTA and STC as possible human carcinogens (class 2B). As a result of too limited or inadequate data, CIT and DON were not classifiable with regard to their carcinogenicity to humans (class 3) [7-9].

In Italy, the consumption of beer has increased over the past few years (about $31.5 \mathrm{~L}$ per person/year in 2016), in particular, of the small-scale brewed beer (called craft beer); an opening of about 500 microbreweries was registered in Italy from 2007 to 2017. In 2016, the Italian Parliament defined as craft beer "the unpasteurized and unfiltered beer produced by micro-breweries, whose 
production is less than 200,000 hectoliters/year" [10]. Craft beer group is a heterogeneous class of beers, sometimes brewed from unusual ingredients; they were scarcely investigated for the content of both healthy and undesirable components, as mycotoxins.

The objective of this study was to evaluate and compare the incidence and contamination level of some mycotoxins, OTA, DON, STC, and CIT, in small- and large-scale brewed beer samples; for both types of beers, the most-sold beers in Italy were collected.

\section{Materials and Methods}

\subsection{Sampling}

A total of 83 samples of small- (SS) and large-scale (LS) brewed beer (42 and 41, respectively) were sampled; for both types of beer, the most-sold beers in Italy were collected (data obtained from IRi reports; Information Resources), representing about $75 \%$ of the total volume of beers sold in Italy. The percentage of beer samples produced in Italy was $47.6 \%(n=20)$ and $41.5 \%(n=17)$ for SS and LS brewed beers, respectively. The majority of LS brewed beers were regular beer (36); the others were wheat beer (3), red (1), and double malt beer (1). Among SS brewed beers, 25 were regular, 6 wheat beer, 5 red, 4 double malt, and 2 dark beer. A representative sampling, putting together at least 3 samples, collected in different retail shops or pubs within a three-month period (June-August 2017), was carried out; the samples were mixed and two subsamples (about $100 \mathrm{~mL}$ each) were kept at $+4{ }^{\circ} \mathrm{C}$. Before the analysis, each sample was gently shaken and degassed by ultrasonication.

\subsection{Reagents and Standards}

The chemicals and solvents used for the extraction and clean-up solutions were ACS grade or equivalent (Carlo Erba, Milan, Italy); deionised water was purified through a Milli-Q treatment system (Millipore, Bedford, MA, USA). For LC-MS/MS analysis, water, methanol, acetonitrile, and formic acid were HPLC grade (Merck, Darmstadt, Germany). Phosphate saline buffer (PBS) was prepared as follows: $\mathrm{NaCl} 8 \mathrm{~g} / \mathrm{L}, \mathrm{KCl} 0.2 \mathrm{~g} / \mathrm{L}, \mathrm{Na}_{2} \mathrm{HPO}_{4} 1.15 \mathrm{~g} / \mathrm{L}, \mathrm{KH}_{2} \mathrm{PO}_{4} 0.2 \mathrm{~g} / \mathrm{L} ; \mathrm{pH}$ 7.4. OTA and trichothecene standard solutions were prepared as described by Bertuzzi et al. [11].

The STC analytical standard was obtained from Sigma-Aldrich (Milan, Italy), while the internal standard $\left[{ }^{13} \mathrm{C}_{18}\right]$-sterigmatocystin $\left(96.4 \%{ }^{13} \mathrm{C}\right)$ was purchased from Biopure (Tulln, Austria) as standard solution in acetonitrile $(1.2 \mathrm{~mL}, 25.7 \mu \mathrm{g} / \mathrm{mL}$, uncertainty $1.02 \mu \mathrm{g} / \mathrm{mL})$. Stock and working STC standard solutions were prepared and calibrated spectrophotometrically as reported by Bertuzzi et al. [12].

The CIT standard (5 mg), purchased as powder from Sigma-Aldrich (Milan, Italy), was dissolved in ethanol $(25 \mathrm{~mL})$, and the solution, after dilution, was calibrated spectrophotometrically at $319 \mathrm{~nm}$ using the value $4710 \mathrm{~L} /(\mathrm{mol} \cdot \mathrm{cm})$ for the absorption coefficient (Neely et al., 1972) and stored at $-20{ }^{\circ} \mathrm{C}$ when not in use. ${ }^{13} \mathrm{C}_{13}$-citrinin internal standard solution (in acetonitrile) was purchased from Romer Labs $(10.6 \mu \mathrm{g} / \mathrm{mL}$; Romer Labs Division Holding GmbH, Getzersdorf, Austria). Working standard solutions, mixed with isotopically-labelled CIT standard solution $(10 \mu \mathrm{g} / \mathrm{mL} ; 90: 10 v / v)$, were prepared by dilution with methanol-water $(30: 70 \mathrm{v} / \mathrm{v})$ in the range between $0.10 \mathrm{and} 5.0 \mu \mathrm{g} / \mathrm{L}$.

\subsection{Analysis for Mycotoxin Determination}

Analysis for OTA and DON quantification was carried out using HPLC-FLD for OTA and GC-MS for DON, according to a previously published method (Bertuzzi et al. [11]).

For STC, an aliquot of degassed sample $(15 \mathrm{~mL})$ was diluted with $15 \mathrm{~mL}$ of PBS, and was then passed through an immunoaffinity column (Easi-extract Sterigmatocystin, R-Biopharm-Rhône, Glasgow, UK). The column was washed with $2 \mathrm{~mL}$ water, then STC was eluted using $6 \mathrm{~mL}$ acetonitrile in a graduated test tube. After concentration under a gentle flow of nitrogen, the purified extract was brought to $1 \mathrm{~mL}$ with acetonitrile-water $40+60 v / v$; then, $900 \mu \mathrm{L}$ was mixed with $100 \mu \mathrm{L}$ of isotopically labelled STC $(12 \mu \mathrm{g} / \mathrm{L})$ in an autosampler vial and injected $(20 \mu \mathrm{L})$ into an LC-MS/MS system consisting of a LC 1.4 Surveyor pump, a Quantum Discovery Max triple-quadrupole mass spectrometer 
(Thermo-Fisher Scientific, San Jose, CA, USA), and a PAL 1.3.1 sampling system (CTC Analytics AG, Zwingen, Switzerland). The system was controlled by Xcalibur 1.4 software (Thermo-Fisher Scientific, Waltham, MA, USA). After separation on a Betasil RP-18 column ( $5 \mu \mathrm{m}$ particle size, $150 \times 2.1 \mathrm{~mm}$, Thermo-Fisher) with a gradient of acetonitrile-water (both acidified with $0.2 \%$ formic acid; flow rate $0.2 \mathrm{~mL} / \mathrm{min}$ ) from 40:60 to 75:25 in $3 \mathrm{~min}$, then, isocratic 40:60 for $6 \mathrm{~min}$; the flow rate was $0.2 \mathrm{~mL} / \mathrm{min}$. The ionisation was performed using positive atmospheric pressure chemical ionisation (APCI) as follows: voltage $4.0 \mathrm{kV}$, sheath and auxiliary gas 29 and 5 psi, respectively, temperature of the heated capillary $270{ }^{\circ} \mathrm{C}$. The mass spectrometric analysis was performed in selected reaction monitoring (SRM). For fragmentation of the $[\mathrm{M}+\mathrm{H}]^{+}$ions (325 and $343 \mathrm{~m} / z$ for STC and $\left[{ }^{13} \mathrm{C}_{18}\right]-\mathrm{STC}$, respectively), argon was used as collision gas at the pressure of 1.5 mTorr. For STC, three transitions were measured: $310 \mathrm{~m} / z$ (24 V) (quantifier), 281 and $253 \mathrm{~m} / z$ (35 V) (qualifiers). For the isotopic label, the transitions were: $327 \mathrm{~m} / z$ (24 V) (quantifier), 297 and $268 \mathrm{~m} / z$ (35 V) (qualifiers).

For CIT, a $15 \mathrm{~mL}$ degassed sample was mixed with $15 \mathrm{~mL}$ PBS and the solution was passed through an immunoaffinity column (Easi-extract Citrinin, R-Biopharm-Rhône, Glasgow, UK). The column was washed with PBS $(2 \mathrm{~mL})$ and CIT was slowly eluted $(0.5 \mathrm{~mL} / \mathrm{min})$ with methanol $(4 \mathrm{~mL})$ into a graduated test tube; the eluate was concentrated under a gentle stream of nitrogen, brought to $1 \mathrm{~mL}$ with methanol-water $(30: 70 \mathrm{v} / \mathrm{v})$ and vortex-mixed for a few seconds. The extract was filtered (Millex HV $0.45 \mu \mathrm{m}$, Merck Millipore, Darmstadt, Germany), then $100 \mu \mathrm{L}$ of internal standard solution $\left({ }^{13} \mathrm{C}_{-} \mathrm{CIT}_{13}, 10.6 \mu \mathrm{g} / \mathrm{L}\right)$ was added to $400 \mu \mathrm{L}$ of purified extract. Analysis was carried out using a HPLC-MS/MS system (see above). CIT was separated on a XBridge BEH RP-18 column $(2.5 \mu \mathrm{m}$ particle size, $100 \times 3.0 \mathrm{~mm}$, Waters Corporation, Milford, MA, USA) with a mobile-phase gradient methanol-water (both acidified with 0.2\% formic acid) from 45:55 to 75:25 in $3 \mathrm{~min}$, then isocratic for $4 \mathrm{~min}$; gradient to $45: 55 \mathrm{in} 1 \mathrm{~min}$ and re-equilibration for $7 \mathrm{~min}$. The flow rate was $0.2 \mathrm{~mL} / \mathrm{min}$; the injection volume was $20 \mu \mathrm{L}$. The ionisation was carried out with an ESI interface (Thermo-Fisher Scientific) in positive mode as follows: spray capillary voltage $4.0 \mathrm{kV}$, sheath and auxiliary gas 35 and 8 psi, respectively, temperature of the heated capillary $270{ }^{\circ} \mathrm{C}$. For fragmentation of $[\mathrm{M}+\mathrm{H}]^{+}$ion $(251 \mathrm{~m} / \mathrm{z})$, the argon collision pressure was set to $1.5 \mathrm{mTorr}$; the selected fragment ions were: $233 \mathrm{~m} / \mathrm{z}$ $(20 \mathrm{~V}), 205$ and $191 \mathrm{~m} / z(28 \mathrm{~V})$. For the isotopic label $\left({ }^{13} \mathrm{C}_{13}\right), 264 \mathrm{~m} / z$ was used as precursor ion with $246 \mathrm{~m} / z(18 \mathrm{~V}), 217$ and $202 \mathrm{~m} / z(26 \mathrm{~V})$ as product ions. Quantitative determination was performed using a LC-Quan software (2.0, Waltham, MA, USA).

\subsection{Performances of the Methods}

The matrix effect in LC-MS/MS is due to the presence of compounds that can co-elute, affecting the ionisation of the analyte. This effect was avoided by the use of isotopically labelled $\left[{ }^{13} \mathrm{C}_{18}\right]-S T C$ and $\left[{ }^{13} \mathrm{C}_{13}\right]$-CIT as internal standard; therefore, the internal standard calibration was applied, adding the isotope-labelled standard to all sample extracts and calibration standards at a fixed concentration.

The linearity of the instrumental measurement was established through five calibration standards in solvent, at different concentrations for each mycotoxin, covering a wide analytical range.

The limit of detection (LOD) was defined as the level corresponding to a signal-to-noise ratio $(\mathrm{S} / \mathrm{N})$ of three in the purified extract for qualifier transition. The limit of quantification (LOQ) was defined in the purified extract as the lowest level for which the repeatability of the analysis was below $10 \%$. The LOD and LOQ were 0.001 and $0.003 \mu \mathrm{g} / \mathrm{L}$ for OTA; 1 and $3 \mu \mathrm{g} / \mathrm{L}$ for DON; 0.001 and $0.003 \mu \mathrm{g} / \mathrm{L}$ for STC; 0.005 and $0.015 \mu \mathrm{g} / \mathrm{L}$ for CIT.

The accuracy of the used methods was evaluated by recovery experiments, performed by spiking a regular, a double malt, and a red beer sample in triplicate at two levels ( $2 \times$ LOQ and $5 \times$ LOQ), for each mycotoxin. The samples were also analysed without spiking, as well as a reagent blank. The spiked sample was allowed to stand for two hours at ambient temperature under a fume hood to allow any residual solvent to evaporate. For each mycotoxin, the average recovery ranged between $86.4 \%$ and $95.6 \%$, with low standard deviations, indicating a satisfactory accuracy and precision for each method. The results of the analyses were corrected for recovery. 


\subsection{Statistical Analysis}

Statistical analysis of mycotoxin contamination data was carried out after common logarithm transformation. This is suggested when the variance of data is higher than the mean. Statistical analysis was run using the package IBM SPSS statistics (ver. 24, 2015 Inc., Chicago, IL, USA). One-way ANOVA was applied to evaluate significant differences between SS and LS beers.

\section{Results and Discussion}

\subsection{Mycotoxin Occurrence in Beer Samples}

The results showed low values of contamination for each mycotoxin, both for SS and LS beer; descriptive statistics (incidence, mean, median, and maximum value) of the results are reported in Table 1; CIT was never detected. For the samples falling between LOD and LOQ, the value was tentatively calculated by proportion with the lowest calibration standard; for the samples showing a concentration lower than LOD, it was considered a contamination level equal to LOD/2.

Table 1. Descriptive statistics for ochratoxin A (OTA), deoxynivalenol (DON), and sterigmatocystin (STC) in small- and large-scale brewed beer.

\begin{tabular}{ccccc}
\hline Beer & & OTA $(\mu \mathrm{g} / \mathrm{L})$ & DON $(\mu \mathrm{g} / \mathrm{L})$ & STC $(\mu \mathrm{g} / \mathrm{L})$ \\
\hline & Positives $(\%)$ & 28.6 & 35.7 & 28.6 \\
Small-scale brewed beer & Mean & $0.005 \pm 0.014$ & $11.3 \pm 20.2$ & $0.002 \pm 0.003$ \\
& Median & $<$ LOD & $<$ LOD & $<$ LOD \\
& Maximum value & 0.070 & 99 & 0.018 \\
\hline & Positives $(\%)$ & 63.4 & 14.6 & 26.8 \\
Large-scale brewed beer & Mean & $0.008 \pm 0.011$ & $5.8 \pm 10.4$ & $0.001 \pm 0.002$ \\
& Median & 0.0048 & $<$ LOD & $<$ LOD \\
& Maximum value & 0.045 & 46 & 0.009 \\
\hline
\end{tabular}

Considering all samples, OTA prevalence was $45.8 \%$ (38 samples), and the average level was $0.007 \pm 0.013 \mu \mathrm{g} / \mathrm{L}$. The maximum value of $0.070 \mu \mathrm{g} / \mathrm{L}$ was found in a regular SS beer; the 95th percentile value was $0.033 \mu \mathrm{g} / \mathrm{L}$. OTA exceeded $0.020 \mu \mathrm{g} / \mathrm{L}$ in only 7 samples $(8.4 \%, 5 \mathrm{LS}$ and $2 \mathrm{SS}$ beers), while it was below $0.010 \mu \mathrm{g} / \mathrm{L}$ in $78.3 \%$ of samples (Figure 1). As regards wheat beer, OTA was detected in 3 of 9 samples with a maximum value of $0.014 \mu \mathrm{g} / \mathrm{L}$. In spite of the different prevalence in SS and LS beer, no significant difference $(p>0.005)$ was observed between their contamination levels.

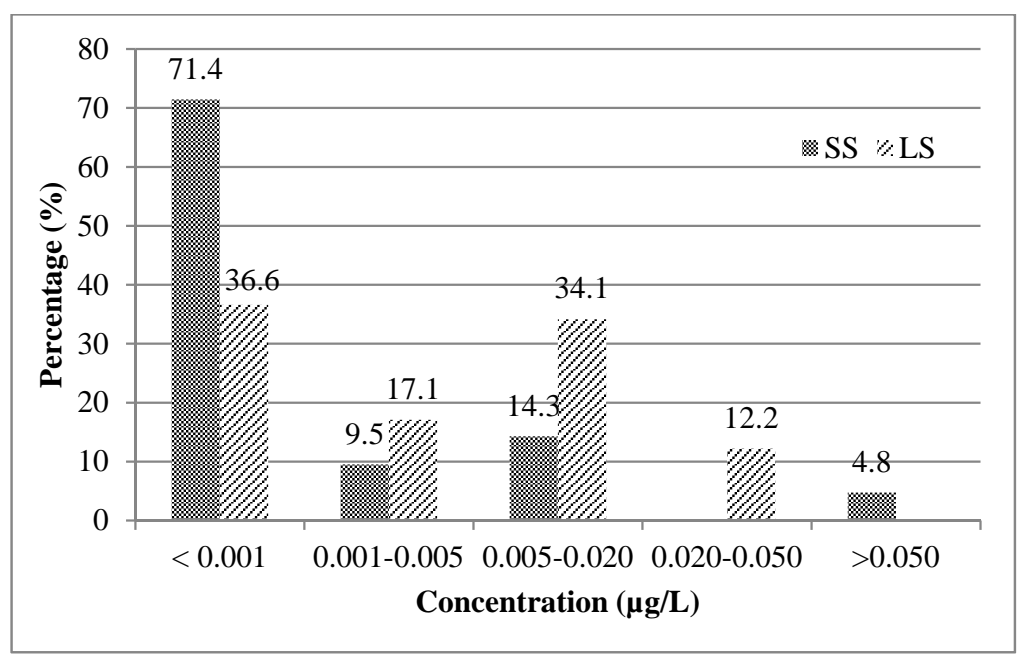

Figure 1. Relative frequency distribution (\%) of ochratoxin A in small- (SS, $n=42)$ and large-scale (LS, $n=41$ ) brewed beer. 
These results were slightly lower than those found in previous European surveys: Varga et al. [13] detected OTA in Hungarian beers at levels of $0.030-0.250 \mu \mathrm{g} / \mathrm{L}$ and Medina et al. [14] at levels of $0.007-0.204 \mu \mathrm{g} / \mathrm{L}$ in beers marketed in Spain. In our previous survey on beers produced in different European countries, an average value for OTA of $0.019 \mu \mathrm{g} / \mathrm{L}$ and an incidence of positives samples of $67.9 \%$ were found [12]. More recently, Lhotska et al. [15] detected OTA in $90 \%$ of Czech beer samples at levels lower than $0.06 \mu \mathrm{g} / \mathrm{L}$; in the same survey, CIT was detected in only 4 of 49 samples (maximum value of $0.19 \mu \mathrm{g} / \mathrm{L}$ ). For craft beer, in a survey on 1000 beer samples, of which $60 \%$ were craft beers [16], OTA was confirmed and quantified by LC-MS analysis in only 5 SS beers at levels ranging from 0.3 to $0.6 \mu \mathrm{g} / \mathrm{L}$. The EU Commission Regulation No. 105/2010 [17] did not fix a maximum level in beer, because the presence of OTA is already controlled in malt (if intended as processed cereal product for direct human consumption, the limit is $3 \mu \mathrm{g} / \mathrm{kg}$ ).

DON prevalence in total samples was $25.3 \%$ (21 samples) and the average level was $8.6 \pm 16.3 \mu \mathrm{g} / \mathrm{L}$. The maximum value of $99 \mu \mathrm{g} / \mathrm{L}$ was detected in a double malt blond SS beer, while the highest level for LS beer was found in a regular beer; the 95th percentile value was $42 \mu \mathrm{g} / \mathrm{L}$. DON concentration exceeded $20 \mu \mathrm{g} / \mathrm{L}$ in $14.5 \%$ of samples, $7 \mathrm{SS}$ and $5 \mathrm{LS}$ beers (Figure 2). For wheat beer, DON was found in $3 \mathrm{SS}$ beers (maximum value of $71 \mu \mathrm{g} / \mathrm{L}$ ). As for OTA, no significant difference was observed between SS and LS beer samples.

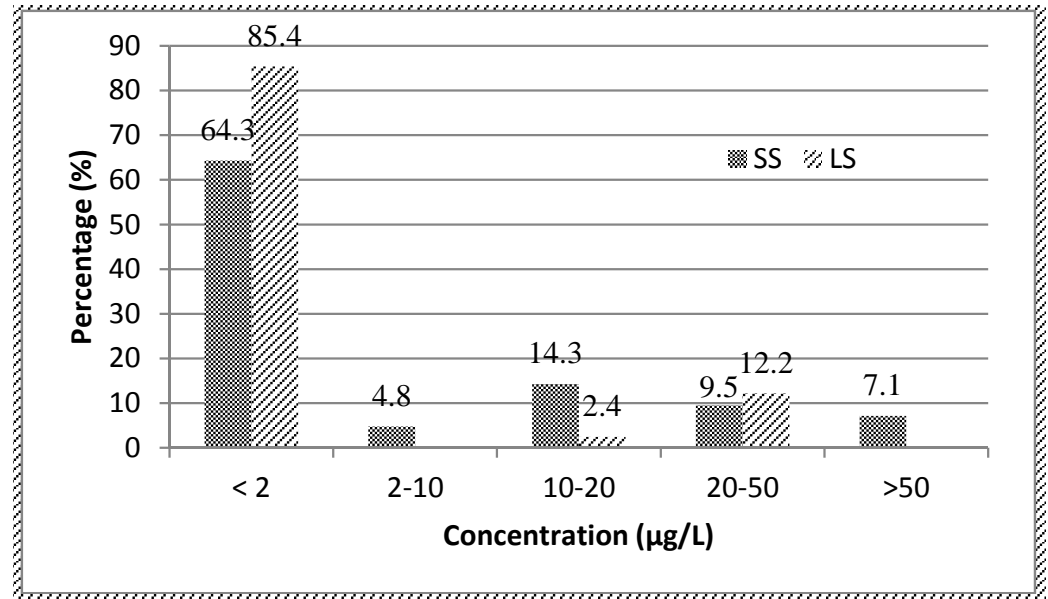

Figure 2. Relative frequency distribution (\%) of deoxynivalenol in small- (SS, $n=42)$ and large-scale (LS, $n=41$ ) brewed beer.

In recent surveys, there seems to be a decreasing trend regarding DON contamination in beer. In a study on 313 European beer samples carried out in 2004 [18], the incidence was $87 \%$, and the contamination ranged between 4.0 and $56.7 \mu \mathrm{g} / \mathrm{L}$; in 40 beer samples collected from Belgian retailers, DON contamination level varied from 2 to $22 \mu \mathrm{g} / \mathrm{L}$ [19]. Kostelanska et al. [20] reported the occurrence of DON, DON-3-glucoside and its acetylated forms; the highest level for DON was $35.9 \mu \mathrm{g} / \mathrm{L}$. In our previous survey [11], DON incidence was $66.0 \%$, and the maximum value was $18.6 \mu \mathrm{g} / \mathrm{L}$. Varga et al. [13] analysed a large number of European beers for DON and deoxynivalenol-3-glucoside (DON-3G) content; the incidence was 77 and $93 \%$, and the mean 8.4 and $6.9 \mu \mathrm{g} / \mathrm{L}$, respectively. In 2016, DON occurrence was detected in $75 \%$ of 44 beer samples collected on German retail market at level ranging from 2.2 to $20 \mu \mathrm{g} / \mathrm{L}$ and showed a median of $3.7 \mu \mathrm{g} / \mathrm{L}$ [21]. As regards craft beer, Peters et al. [16] reported a higher average contamination in SS beer $(63 \mu \mathrm{g} / \mathrm{L})$ compared to LS beers $(39 \mu \mathrm{g} / \mathrm{L})$ using a 6-plex microsphere immunoassay; however, the confirmatory analysis by LC-MS/MS often reported lower values. Finally, low incidence (32\%) but high concentration values in positive samples were found in SS Brazilian beer, with levels ranging from $127 \mu \mathrm{g} / \mathrm{L}$ to $501 \mu \mathrm{g} / \mathrm{L}$, and a mean of $221 \mu \mathrm{g} / \mathrm{L}$ [22].

STC was found in $27.7 \%$ (23 samples) of samples, showing a similar prevalence in SS and LS beers. The contamination was at low levels; the average value in all samples was $0.001 \pm 0.003 \mu \mathrm{g} / \mathrm{L}$. STC level 
exceeded $0.010 \mu \mathrm{g} / \mathrm{L}(0.018 \mu \mathrm{g} / \mathrm{L})$ in only one sample (regular SS beer) and the 95th percentage value was $0.008 \mu \mathrm{g} / \mathrm{L}$; STC contamination was in the range $0.005-0.010 \mu \mathrm{g} / \mathrm{L}$ in $14.4 \%$ ( $n=12 ; 7 \mathrm{SS}$ and 5 LS beers) of samples (Figure 3). For wheat beer, STC was detected in 2 SS beers at levels close to $0.005 \mu \mathrm{g} / \mathrm{L}$.

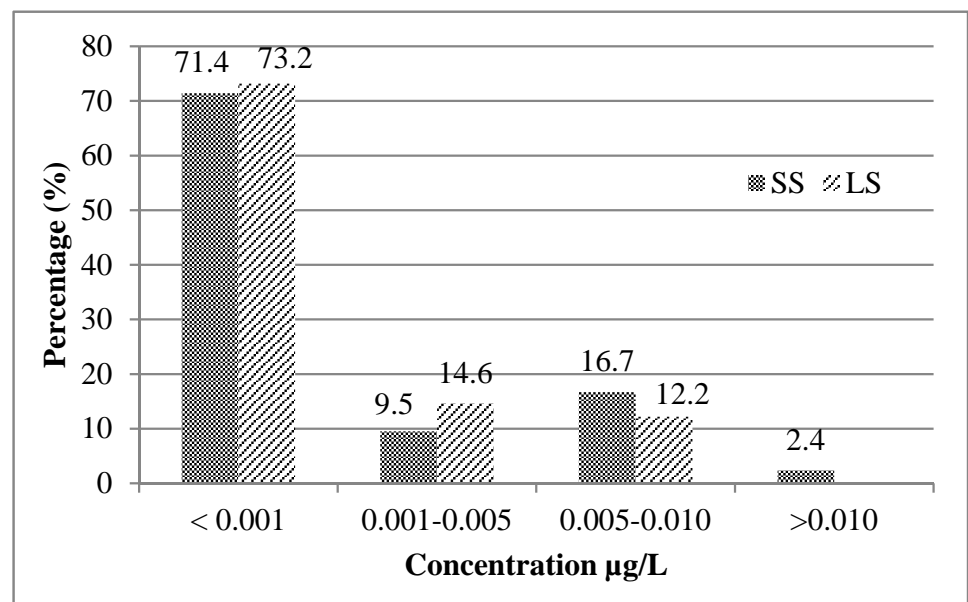

Figure 3. Relative frequency distribution (\%) of sterigmatocystin in small- (SS, $n=42)$ and large-scale (LS, $n=41$ ) brewed beer.

Few results on STC contamination of beer have been reported in the scientific literature; its occurrence in beer has been detected by Versilovskis et al. [23] in 2 of 26 Latvian beers $(4-8 \mu \mathrm{g} / \mathrm{L}$, one light, one dark beer); in a recent survey on STC in cereals and derived products, STC was never found in 53 LS European beer samples [24].

\subsection{Mycotoxin Co-Occurrence}

OTA, DON, and STC were never detected together, while a contamination with two mycotoxins was observed in 19.3\% (16 samples; 11 LS beers) of samples. Co-occurrence of OTA and DON was found in only two (2.4\%) samples; STC occurred with OTA and DON in 8 and 6 samples, respectively. Mycotoxin contamination can occur at different times, during cereal growth in field, post-harvest or during malting. As regards OTA, P. verrucosum is a common contaminant of stored cereals [1], then, OTA occurrence in beer samples generally indicates contamination during storage and/or malting processing. On the other hand, DON and STC can be mainly produced during growth in field, while their production in stored grain is limited [24-26].

\subsection{Estimation of Mycotoxin Dietary Intakes by Beer Consumption}

Considering the average values of OTA, DON, and STC for SS and LS beers obtained from this survey, the mean Italian beer consumption ( $31.5 \mathrm{~L} /$ year per capita, equivalent to $0.086 \mathrm{~L} /$ day) and a body weight of $60 \mathrm{~kg}$, it was possible to calculate the daily average exposure (Table 2).

Table 2. Estimation of mycotoxin dietary intakes from small- (SS) and large-scale (LS) brewed beer consumed in Italy.

\begin{tabular}{|c|c|c|c|c|c|c|c|}
\hline \multirow[t]{2}{*}{ Mycotoxin } & \multicolumn{2}{|c|}{$\begin{array}{c}\text { Daily Average Exposure } \\
\left(\mu \mathrm{g} / \mathrm{kg}_{\mathrm{bw}}\right)\end{array}$} & \multirow[t]{2}{*}{$\begin{array}{c}\text { Maximum Daily } \\
\text { Exposure }\left(\mu \mathrm{g} / \mathrm{kg}_{\mathrm{bw}}\right)\end{array}$} & \multirow[t]{2}{*}{$\begin{array}{c}\text { Tolerable Daily } \\
\text { Intake }\left(\mu \mathrm{g} / \mathrm{kg}_{\mathrm{bw}}\right)\end{array}$} & \multicolumn{3}{|c|}{$\%$ of Tolerable Daily Intake } \\
\hline & SS beer & LS beer & & & SS beer & LS beer & Max level \\
\hline OTA & 0.000007 & 0.000011 & 0.00010 & 0.017 & 0.04 & 0.067 & 0.59 \\
\hline DON & 0.0162 & 0.0083 & 0.1419 & 1 & 1.62 & 0.83 & 14.2 \\
\hline STC & 0.0000028 & 0.0000014 & 0.0000258 & / & / & / & / \\
\hline
\end{tabular}


The European Food Safety Authority (EFSA) indicated a tolerable weekly intake (TWI) for OTA of $120 \mathrm{ng} / \mathrm{kg}_{\mathrm{bw}}$, (equivalent to a TDI of $0.017 \mu \mathrm{g} / \mathrm{kg}_{\mathrm{bw}}$ ), while the Scientific Committee for Food (SCF) indicated a TDI of $1 \mu \mathrm{g} / \mathrm{kg}_{\mathrm{bw}}$ for DON; no health-based guidance value has been established for STC. The calculated mycotoxin intakes shown in Table 2 are reassuring; even if these data were obtained from a limited survey carried out in a short sampling period, the daily average exposure for an Italian moderate consumer of both small- and large-scale brewed beer, seems to be very low, in agreement with previous studies $[11,27,28]$. Considering the maximum values found in this survey, the daily intake is not negligible for DON.

\section{Conclusions}

Several surveys have been carried out on mycotoxin occurrence in beer; in the last years, the results often reported low contamination levels for LS brewed beers, showing that raw materials and brewing processes are careful controlled. This survey confirmed this trend and reported low contamination levels both for industrial and craft beer. No significant difference was observed between SS and LS beers, even if the collected samples do not represent all categories of both large- and small-scale brewed beer. The contamination does not seem particularly worrying, and the levels found should not represent a serious risk for consumers' health.

Author Contributions: For research articles with several authors, a short paragraph specifying their individual contributions must be provided. The following statements should be used "Conceptualization, T.B. and G.D.; Methodology, T.B.; Software, G.D.; Validation, A.M. and S.R.; Formal Analysis, S.R. and A.M.; Investigation, S.R. and A.M.; Resources, T.B.; Data Curation, T.B. and A.P.; Writing-Original Draft Preparation, T.B. and A.P.; Writing-Review \& Editing, T.B. and A.P.; Visualization, T.B.; Supervision, T.B.; Project Administration, T.B.; Funding Acquisition, UCSC", please turn to the CRediT taxonomy for the term explanation. Authorship must be limited to those who have contributed substantially to the work reported.

Funding: The present work was supported by the European Foundation for Alcohol Research (ERAB, Project EA 15 42).

Conflicts of Interest: The authors declare no conflicts of interest.

\section{References}

1. Baxter, E.D.; Slaiding, I.R.; Kelly, B. Behaviour of ochratoxin A in brewing. J. Am. Soc. Brew. Chem. 2001, 59, 98-100.

2. Schwarz, P.B.; Casper, H.H.; Beattie, S. Fate and development of naturally occurring Fusarium mycotoxins during malting and brewing. J. Am. Soc. Brew. Chem. 1995, 53, 121-127.

3. Mizutani, K.; Nagatomi, Y.; Mochizuki, N. Metabolism of zearalenone in the course of beer fermentation. Toxins 2011, 3, 134-141. [CrossRef] [PubMed]

4. Pietri, A.; Bertuzzi, T.; Agosti, B.; Donadini, G. Transfer of aflatoxin $\mathrm{B}_{1}$ and fumonisin $\mathrm{B}_{1}$ from naturally contaminated raw materials to beer during an industrial brewing process. Food Addit. Contam. 2010, 27, 1431-1439. [CrossRef] [PubMed]

5. EFSA. Scientific Opinion on the risks for public and animal health related to the presence of citrinin in food and feed. EFSA Panel on Contaminants in the Food Chain. EFSA J. 2012, 10, 2605. [CrossRef]

6. EFSA CONTAM Panel (EFSA Panel on Contaminants in the Food Chain). Scientific Opinion on the risk for public and animal health related to the presence of sterigmatocystin in food and feed. EFSA J. 2013, 11, 3254. [CrossRef]

7. International Agency for Research on Cancer. Some naturally occurring and synthetic food components, furocoumarins and ultraviolet radiation. In IARC Monographs on the Evaluation of Carcinogenic Risk to Humans; IARC, World Health Organization: Lyon, France, 1986; pp. 40-67.

8. International Agency for Research on Cancer. Some naturally occurring substances: Food items and constituents, heterocyclic aromatic amines and mycotoxins. In IARC Monographs on the Evaluation of Carcinogenic Risk to Humans; IARC, World Health Organization: Lyon, France, 1993; Volume 56, pp. 245-395.

9. International Agency for Research on Cancer. Aflatoxins IARC Monograph on the Evaluation of Carcinogenic Risks to Humans; IARC, World Health Organization: Lyon, France, 2002; Volume 82, pp. 171-300. 
10. Gazzetta Ufficiale della Repubblica Italiana (GU). Act of the Legislature, DDL S 1328-B, 28 July $2016 \mathrm{n}^{\circ} 154$, GU 186 of 10 August 2016.

11. Bertuzzi, T.; Rastelli, S.; Mulazzi, A.; Donadini, G.; Pietri, A. Mycotoxin occurrence in beer produced in several European countries. Food Control 2011, 22, 2059-2064. [CrossRef]

12. Bertuzzi, T.; Romani, M.; Rastelli, S.; Mulazzi, A.; Pietri, A. Sterigmatocystin Occurrence in Paddy and Processed Rice Produced in Italy in the Years 2014-2015 and Distribution in Milled Rice Fractions. Toxins 2017, 9, 86. [CrossRef] [PubMed]

13. Varga, J.; Kiss, R.; Matrai, T.; Teren, J. Detection of ochratoxin A in Hungarian wines and beers. Acta Aliment. 2005, 34, 381-392. [CrossRef]

14. Medina, A.; Jimenez, M.; Gimeno Adelantado, J.V.; Valle Algarra, F.M.; Mateo, R. Determination of ochratoxin A in beer marketed in Spain by liquid chromatography with fluorescence detection using lead hydroxyacetate as a cleanup agent. J. Chromatogr. A 2005, 1083, 7-13. [CrossRef] [PubMed]

15. Lhotská, I.; Šatínský, D.; Havlíková, L.; Solich, P. A fully automated and fast method using direct sample injection combined with fused-core column on-line SPE-HPLC for determination of ochratoxin A and citrinin in lager beers. Anal. Bioanal. Chem. 2016, 408, 3319-3329. [CrossRef] [PubMed]

16. Peters, J.; van Dam, R.; van Doorn, R.; Katerere, D.; Berthiller, F.; Haasnoot, W.; Nielen, M. Mycotoxin profiling of 1000 beer samples with a special focus on craft beer. PLoS ONE 2017, 12, e0185887. [CrossRef] [PubMed]

17. Commission of the European Communities. Commission Regulation (EC) No 105/2010 of 5 February 2010 amending Regulation (EC) No 1881/2006 setting maximum levels for certain contaminants in foodstuffs as regards ochratoxin A. Off. J. Eur. Union 2010, L 35, 7-8.

18. Papadopoulou-Bouraoui, A.; Vrabcheva, T.; Valzacchi, S.; Stroka, J.; Anklam, E. Screening survey of deoxynivalenol in beer from the European market by an enzyme-linked immunosorbent assay. Food Addit. Contam. 2004, 21, 607-617. [CrossRef] [PubMed]

19. Anselme, M.; Tangni, E.; Pussemeier, L.; Motte, J.C.; Hove, F.; van Schneider, Y.J.; Peteghem, C.; van Larondelle, Y. Comparison of ochratoxin A and deoxynivalenol in organically and conventionally produced beers sold on the Belgiam market. Food Addit. Contam. 2006, 23, 910-918. [CrossRef] [PubMed]

20. Kostelanska, M.; Hajslova, J.; Zachariasova, M.; Malachova, A.; Kalachova, K.; Poustka, J.; Fiala, J.; Scott, P.M.; Berthiller, F.; Krska, R. Occurrence of deoxynivalenol and its major conjugate, deoxynivalenol-3-glucoside, in beer and some brewing intermediates. J. Agric. Food Chem. 2009, 57, 3187-3194. [CrossRef] [PubMed]

21. Bauer, J.; Gross, M.; Gottschalk, C.; Usleber, E. Investigations on the occurrence of mycotoxins in beer. Food Control 2016, 63, 135-139. [CrossRef]

22. Piacentini, K.C.; Savi, G.D.; Olivo, G.; Scussel, V.M. Quality and occurrence of deoxynivalenol and fumonisins in craft beer. Food Control 2015, 50, 925-929. [CrossRef]

23. Veršilovskis, A.; De Saeger, S.; Mikelsone, V. Determination of sterigmatocystin in beer by high performance liquid chromatography with ultraviolet detection. World Mycotoxin J. 2008, 1, 161-166. [CrossRef]

24. Mol, H.; Mac Donald, S.; Anagnostopoulos, C.; Spanjer, M.; Bertuzzi, T.; Pietri, A. European survey on sterigmatocystin in cereals, cereals-based products, beer and nuts. World Mycotoxin J. 2016, 9, 633-642. [CrossRef]

25. Baxter, E.D.; Byrd, N.; Slaiding, I.R. Food Safety Review of UK Cereal Grain for Use in Malting, Milling and Animal Feed; HGCA Project Report; Campden BRI: Gloucestershire, UK, 2009; pp. 464-522.

26. Magan, N.; Aldred, D. Post-harvest control strategies: Minimizing mycotoxins in the food chain. Int. J. Food Microbiol. 2007, 119, 131-139. [CrossRef] [PubMed]

27. Harcz, P.; Tangni, E.K.; Wilmart, O.; Moons, E.; Peteghem, C.; van Saeger, S.; de Schneider, Y.J.; Larondelle, Y.; Pussemeier, L. Intake of ochratoxin A and deoxynivalenol through beer consumption in Belgium. Food Addit. Contam. 2007, 24, 910-916. [CrossRef] [PubMed]

28. Gumus, T.; Arici, M.; Demirci, M. A survey of barley, malt and beer contamination with OTA in Turkey. J. Inst. Brew. 2004, 110, 146-149. [CrossRef]

(C) 2018 by the authors. Licensee MDPI, Basel, Switzerland. This article is an open access article distributed under the terms and conditions of the Creative Commons Attribution (CC BY) license (http:/ / creativecommons.org/licenses/by/4.0/). 